\title{
The Effects of a Sub-Anaesthetic Dose of Ketamine on Human Selective Attention
}

\author{
B. Oranje, M.A., B.N.M. van Berckel, M.D., Ph.D., C. Kemner, M.D., Ph.D., J.M. van Ree, Ph.D., \\ R.S. Kahn, M.D., Ph.D., and M.N. Verbaten, Ph.D.
}

A growing number of studies demonstrate that antagonists of the N-methyl-D-aspartate (NMDA) receptors can induce a broad range of psychophysiological anomalies in healthy subjects similar to those observed in schizophrenia. In this study, the effect of a sub-anaesthetic dose of the non-

competitive NMDA antagonist, ketamine, on human selective attention was explored. It was hypothesized that ketamine would induce in healthy subjects

psychophysiological anomalies that are commonly observed in schizophrenic patients, such as reduced P300 amplitude and a reduction of both mismatch negativity (MMN) and processing negativity $(P N)$. In a double-blind randomized placebo-controlled design, healthy male volunteers $(\mathrm{n}=18)$ were challenged with a sub-anaesthetic dose of ketamine $(0.3 \mathrm{mg} / \mathrm{kg}$ iv) after which they were tested in a selective attention task. In this task, two types of stimuli were evenly presented to the left or right ear: standard tones $(80 \%)$ and deviant tones (20\%) of either 1000 or $1100 \mathrm{~Hz}$. The duration of a stimulus $(95 \mathrm{~dB})$ was $50 \mathrm{~ms}$, the interstimulus intervals were randomized between 1750 and $2150 \mathrm{~ms}$. The volunteer was instructed to push a button as quickly as possible after hearing the deviant tone in a specified ear. Ketamine did not alter performance of the subjects: in both the placebo and drug condition their reaction times for and percentages of hits and false alarms did not differ. Ketamine did, however, reduce PN and the P300 amplitude (both in general and to deviant stimuli in particular). However, no drug effect on MMN was found. In addition, ketamine enhanced the N100 amplitude to deviant stimuli. In conclusion, ketamine induces some of the attentional deficits in healthy controls that are observed in schizophrenic patients. Consequently, reduced glutamatergic activity in the brain may be involved in some of the symptoms of schizophrenia.

[Neuropsychopharmacology 22:293-302, 2000] (C) 2000 American College of Neuropsychopharmacology. Published by Elsevier Science Inc.
KEY WORDS: Mismatch negativity; Processing negativity; P300; NMDA; Ketamine; Selective attention;

Schizophrenia

Schizophrenia is a chronic and prevalent psychiatric disorder with an estimated lifetime prevalence of $1 \%$ in

From the Department of Psychiatry (BO, BNMVB, RSK), Department of Child and Adolescent Psychiatry (CK), the Rudolf Magnus Institute for Neurosciences (JMVR, MNV), the Faculty of Pharmacy, Department of Psychopharmacology (MNV), University Hospital Utrecht, Utrecht, The Netherlands

Address correspondence to: B. Oranje, Department of Psychiatry, University Hospital Utrecht, PO Box 85500, 3508 GA, Utrecht, the Netherlands.

Received February 1, 1999; revised August 17, 1999; accepted September 9, 1999. the general population. The symptoms of schizophrenia can be divided into those that are positive (reflecting an excess of normal behavior such as delusions and hallucinations), and those that are negative (reflecting a loss of normal behavior such as social withdrawal and affective flattening). In addition to positive and negative symptoms, schizophrenic patients show cognitive deficits such as a limited ability to use and direct their attention. For example, schizophrenic patients seem less able to detect and process novel stimuli than healthy controls (e.g., reduced ability in the detection of infrequent stimuli in a sequence of frequent stimuli (BaribeauBraun et al. 1983)). Furthermore, as McGhie and Chapman already noted in 1961, schizophrenic patients are less able to direct their attention to one of several 
sources of incoming information than are healthy controls (McGhie and Chapman 1961). In other words, schizophrenic patients exhibit a loss in the selective function of attention. These deficits in attention can be quantified by assessment of event related brain potentials (ERPs) (Friedman 1991; Venables 1991).

The inability of schizophrenic patients to select relevant from irrelevant information can be assessed by measuring their processing negativity (PN). Processing negativity (sometimes referred to as $\mathrm{Nd}$ ) is elicited whenever stimuli have to be attended to that differ in some physical feature (spatial position or frequency) from other stimuli. This negativity represents a cerebral comparison or matching process by which the brain selects these relevant stimuli from the irrelevant stimuli (Näätänen 1990). PN is reduced in schizophrenic patients (Pritchard 1986) and correlates negatively with both negative and positive symptomatology (Ward et al. 1991).

The inability of schizophrenic patients to detect infrequent stimuli (deviants) in a sequence of frequent stimuli (standards) can be studied by assessing mismatch negativity (MMN). This negativity represents the functioning of an automatic stimulus-deviation detection process. This pre-attentive process compares an incoming stimulus with stimuli stored in the auditory sensory memory. It automatically sends an interrupt to the central processing channel whenever an auditory stimulus is either not represented in the auditory memory system or has a label "significant" (in the case the individual has to react on the stimulus) (Öhman 1979; Näätänen 1979). In schizophrenic patients, MMN is reduced as compared to healthy controls (Oades et al. 1997; Javitt et al. 1993, 1995; Shelley et al. 1991). Since MMN correlates negatively with negative symptomatology only, it might be useful as a discriminator between negative and positive symptoms in schizophrenia (Catts et al. 1995).

Another method of measuring the inability to detect infrequent stimuli in a sequence of frequent stimuli is by assessment of the P300. Similar to MMN, the P300 is elicited by infrequent stimuli (deviants) appearing in a sequence of frequent stimuli (standards), with the additional feature that these deviant stimuli are previously designated as being target stimuli, and thus require attention.The P300 is inversely proportional to target probability and is assumed to reflect aspects of further (conscious) processing of the stimulus that is being attended to (Näätänen 1990). Further evidence for this assumption is presented in the study of Javitt et al. (1995), who found that the decrement in MMN amplitude was correlated significantly with the decrement in P300 amplitude in schizophrenic subjects.

In a number of studies, schizophrenic patients show a reduction of the $\mathrm{P} 300$ as compared to healthy controls (e.g., Boutros et al. 1997; Javitt et al. 1995; Pritchard 1986; Baribeau-Braun et al. 1983). Similar to MMN, the
P300 correlates negatively with the negative symptomatology of schizophrenia (Pritchard 1986). In addition, the P300 shows a positive correlation with the clinical outcome in terms of social functioning of schizophrenic patients (Strik et al. 1996). There is also some evidence that a reduced P300 is trait-dependent in patients suffering from schizophrenia (Juckel et al. 1996).

All three ERP-components mentioned above can be measured in a special kind of auditory oddball task, the so called selective attention task (Jonkman et al. 1997; Näätänen 1990; Näätänen et al. 1993; Sams et al. 1985; Woldorff et al. 1991; Woldorff and Hillyard 1991). In this task, usually two types of auditory stimuli are presented to the left and right ear: a frequently appearing standard stimulus and an occasionally appearing deviant stimulus. Subjects are asked to attend (push a button) to the deviant stimulus in a previously designated ear (or 'channel). In addition to the ERP-components this task provides behavioural measures ( $\%$ hits, $\%$ false alarms and response time).

The mechanisms that mediate these attentional processes are unclear. However, there is some indication for the involvement of N-Methyl-D-Aspartate (NMDA) receptors: both competitive and non-competitive NMDA antagonists reduce MMN in monkeys (Javitt et al. 1996). Interestingly, several lines of evidence suggest the NMDA system to be involved in schizophrenia. For instance, in post-mortem studies, an abnormally low level of glutamate is found in patients with schizophrenia when compared to healthy controls (Tsai et al. 1995; Toru et al. 1988). Moreover, van Berckel et al. (1996) found that a partial agonist of the NMDA receptor (d-cycloserine) reduced negative symptoms in medication-free schizophrenic patients. In addition, antagonists of the NMDA receptors, like ketamine, phencyclidine (PCP) or selfotel, induce a broad range of psychological symptoms in nonschizophrenic subjects that resemble some of the symptoms observed in schizophrenia (Ellison 1995; Krystal et al. 1994; Grotta et al. 1995; Malhotra et al. 1996; Domino et al. 1965; Luby et al. 1962). Finally, ketamine exacerbates the positive symptoms of schizophrenic patients (Lahti et al. 1995).

The current study was designed to indirectly explore the role of NMDA receptors in human selective attention by administering ketamine, a non-competitive NMDA antagonist, to healthy subjects and measuring their performance in a selective attention task. It was expected that ketamine would induce symptoms in healthy subjects that mimic those found in schizophrenic patients, i.e., an increase in errors during task performance at the behavioural level and a reduction of mismatch negativity, processing negativity and of the P300, at the ERP-level. Since the interstimulus intervals used in this study are relatively large, the processing negativity was not expected to coincide with the N100 amplitude. 


\section{MATERIALS AND METHODS}

\section{Subjects}

Healthy male volunteers were recruited through university newspaper advertisements. Only physically healthy subjects without a personal or family history in first-degree relatives with psychiatric illness were included. The study was approved by the Human Ethics Board of the University Medical Center Utrecht. After written and oral information had been given, written informed consent was obtained from all subjects before enrollment in the study. Subsequently, they were interviewed using the Comprehensive Assessment of Symptoms and History (CASH) (Andreasen et al. 1992) and the Schedule for Affective Disorders and Schizophrenia, Life time version (SADS-L) (Endicott and Spitzer 1978) to assess for psychiatric illnesses. They also underwent a full physical examination including an electrocardiogram and routine laboratory tests (complete blood count, urine analysis and a urine toxicology screen for drug use). In addition, volunteers were screened for hearing deficits by using an audiometer at 500, 1000, and $6000 \mathrm{~Hz}$. Volunteers who could not detect tones at $20 \mathrm{~dB}$ were excluded.

Twenty-one volunteers passed the screening tests, of whom two did not show an identifiable startle reflex and were therefore excluded. Thus, 19 subjects proceeded to the active phase of the study. One subject had severe nausea during the ketamine session and the procedure was interrupted leaving 18 subjects who completed both test days. Subjects had a mean age of 23.7 years ( $\mathrm{SD}=2.4$; range: 20 to 28 years) a mean length of $183 \mathrm{~cm}(\mathrm{SD}=7 \mathrm{~cm})$, a mean weight of $75 \mathrm{~kg}(\mathrm{SD}=8 \mathrm{~kg})$ and a mean body-mass index (Quatelet index) of 21.9 $(\mathrm{SD}=2.1)$.

\section{Experimental Design}

In a randomized, double-blind, placebo-controlled cross-over experiment, subjects received ketamine or placebo on two separate occasions, a minimum of one week apart. Psychophysiological (PPI, P50 reduction, selective attention), neuro-endocrine (luteinizing hormone (LH) and cortisol), ketamine and nor-ketamine plasma levels, physiological (blood-pressure and heart rate), biochemical (homovanillic acid (HVA)), and behavioural measures were collected over a 4.5 -hour period during each session. In addition, three psychometric tests were assessed: the Brief Psychiatric Rating Scale (BPRS), the Profile of Mood Scale (POMS), and the Visual Analog mood Scale (VAS). The results of the suppression of the P50, inhibition of the startle reflex, and the psychometric tests mentioned above, are reported elsewhere (van Berckel et al. 1998).

Subjects arrived at the research ward of the Department of Psychiatry, University Hospital Utrecht at 8:30 a.m., having fasted since 11:00 p.m. the preceding day. Two indwelling venous catheters were inserted into the antecubital vein of each arm. Each catheter was kept open with $1 \mathrm{ml}$ heparin (100 Units $/ \mathrm{ml})$, infused after each blood sample. At 10:00 a.m., infusion was started through one of the intravenous catheter using an IVAC 711 automatic infusion pump. Ketamine was infused in the following amounts and time-frames: $0.3 \mathrm{mg} / \mathrm{kg}$ during the loading phase (first 40 minutes), $0.0495 \mathrm{mg} / \mathrm{kg}$ during the next ten minutes, and $0.213 \mathrm{mg} / \mathrm{kg}$ for the sustaining phase (last 85 minutes). The purpose of the sustaining phase is to achieve a pseudo-steady state concentration (see also van Berckel et al. 1998). In the final 75 minutes of this pseudo-steady state period, the psychophysiological assessments were made. Blood samples were collected 20,40, 80, 105, 135, 165, 195, and 240 minutes after start of the infusion. In addition at 10, 20, 30, 40, 50, 80, 105, 135, 165, 195, and 240 minutes, blood pressure and heart rates were assessed. Furthermore, at $0,40,135$, and 240 minutes, behavioural measurements were made. Blood samples were collected in ice-cold $10 \mathrm{ml}$ plastic tubes containing EDTA. They were centrifuged (10 minutes at $3000 \mathrm{rev} /$ minute at $4^{\circ} \mathrm{C}$ ) within 25 minutes of sampling and stored on ice until then. Plasma was transferred in plastic tubes and stored at $-80^{\circ} \mathrm{C}$ until the time of the assays.

\section{Signal Recording}

Electroencephalogram (EEG) recordings were made with an electrocap (tin electrodes) from 31 scalp locations (10-20 system). However, only data from the electrodes relevant for the present study were analysed (i.e., where the maximum activity for the ERPs measured was to be expected): the midline electrodes $\mathrm{Fz}$, $\mathrm{Cz}$, and Pz. The left mastoid was used as a reference. Horizontal electro-occulogram (EOG) recordings were made from tin electrodes placed to the outer canthus of each eye. Similarly, vertical EOG was recorded from electrodes placed infra-orbital and supra-orbital to the left eye. The right eye was used for electro-myography (EMG) measurement of the orbiculus oculi. For all signal recordings, a ground electrode was attached to the middle of the forehead. Impedance was kept below $5 \mathrm{k} \Omega$. EEG and EOG signals were recorded with a time constant set to $5 \mathrm{~s}$, and EMG signals with a time constant set to $50 \mathrm{~ms}$. All signals were filtered on-line at $40 \mathrm{~Hz}$ and were digitized on line by a computer at a rate of $256 \mathrm{~Hz}$. Sampling started $100 \mathrm{~ms}$ before stimulus onset and lasted $1 \mathrm{~s}$.

\section{Procedure}

The subjects were brought to a soundproof, electrically shielded experimental cabin, where they were seated in a dentist chair. A vacuum cushion was attached to the 
top of the chair, for restrain of the subject's head in such a way that he faced the centre of the TV screen and did not move.

During each test session, three tasks were presented: the prepulse inhibition of the startle reflex, the P50, and the auditory selective attention task. The order of the tasks was balanced across subjects.

The selective attention task (see also Jonkman et al. 1997) consisted of 300 stimuli presented in such a way that they randomly were perceived in either the right or the left ear. Two types of stimuli could be distinguished: standard tones, which appeared in $80 \%$ x of the cases, and deviant tones, which appeared in the resulting $20 \%$ of the cases. The stimuli were evenly presented to the left or right ear (attended deviants were never presented immediately after each other). The subject was instructed to push a button as fast as possible if the deviant tone occurred in a previously designated ear. Ear designation was balanced randomly across the subjects.

After this initial task the subjects were presented the next auditory selective attention task in which they had to monitor the other ear for deviant stimuli. The attribute used to define stimulus type was tone frequency (either 1000 or $1100 \mathrm{~Hz}$ ): the tone frequency defined as standard or deviant was balanced across subjects. The duration of a stimulus ( $95 \mathrm{~dB}$ ) was $50 \mathrm{~ms}$ and the interstimulus intervals (ISIs) were randomized between 1750 and $2150 \mathrm{~ms}$. During the task, the subjects had to maintain their gaze at a fixation cross in the middle of the TV screen.

\section{Signal Analysis}

Electroencephalogram and EOG data of the selective attention task were analysed using a software package especially designed for EEG and ERP data processing. First, all of the sampled EEG and EOG epochs were baseline corrected and filtered off-line using a $30 \mathrm{~Hz}, 24$ $\mathrm{dB} /$ octet digital low-pass filter. Second, the EEG was corrected for vertical EOG artifacts by subtracting vertical EOG from EEG epochs by a regression method in the time domain (Kenemans et al. 1991). Last, all EEG epochs containing artifacts (saturation of the A/D convertor or an amplitude greater than -100 or $100 \mu \mathrm{V}$ ) were removed from the database. The following time windows were used for peak scoring: the N100 was scored between 50 and $150 \mathrm{~ms}$, the P300 between 300 and $600 \mathrm{~ms}$, processing negativity between 150 and 350 $\mathrm{ms}$, and mismatch negativity was scored between 200 and $400 \mathrm{~ms}$.

\section{Statistical Analysis}

The P300 and N100 ERPs were analysed by means of planned comparisons using ANOVA for dependent measures (within subject design). The leads analysed were Pz in the case of the P300 and $\mathrm{Cz}$ in the case of the N100. Since an effect of stimulus type was expected, a planned comparison was done for the P300 wave form elicited by standard and deviant stimuli at electrode Pz. The three within-factors were: condition (ketamine or placebo), attention (stimulus in attended channel or unattended channel), and stimulus type (standard or deviant). Similarly, planned comparisons were made for the difference waves (MMN and $\mathrm{PN}$ ), using $\mathrm{Fz}$ in both cases. Student $\mathrm{t}$-tests were used to analyse the behavioural responses (hits, misses, false-alarms) and the difference waves.

\section{RESULTS}

\section{Ketamine and Nor-Ketamine Plasma Levels}

Ketamine infusion produced a rapid increase in plasma concentration $[\mathrm{F}(1,17)=78.7 ; p<.001]$ (Figure 1). At the end of the loading phase, ketamine plasma concentration reached a maximum of $158 \mathrm{ng} / \mathrm{ml}( \pm 64 \mathrm{ng} / \mathrm{ml}$, SD) declining with approximately $15 \%$ to the pseudosteady state concentration of $134 \mathrm{ng} / \mathrm{ml}( \pm 31 \mathrm{ng} / \mathrm{ml}, \mathrm{SD})$, which was reached at 60 minutes after start of the infusion. During this period, plasma concentrations remained within $129 \mathrm{ng} / \mathrm{ml}( \pm 29 \mathrm{ng} / \mathrm{ml}, \mathrm{SD})$ and $138 \mathrm{mg} / \mathrm{ml} \mathrm{( \pm}$ $21 \mathrm{ng} / \mathrm{ml}, \mathrm{SD})$. Plasma concentrations of nor-ketamine, the major metabolite of ketamine, increased gradually with a maximum of $99 \mathrm{ng} / \mathrm{ml}( \pm 27 \mathrm{ng} / \mathrm{ml}, \mathrm{SD})$ at 165 minutes after start of the infusion $[\mathrm{F}(1,17)=86.5 ; p<.001)$.

\section{Performance}

Three kinds of performance measures were obtained: percentage of hits, percentage of false alarms and mean

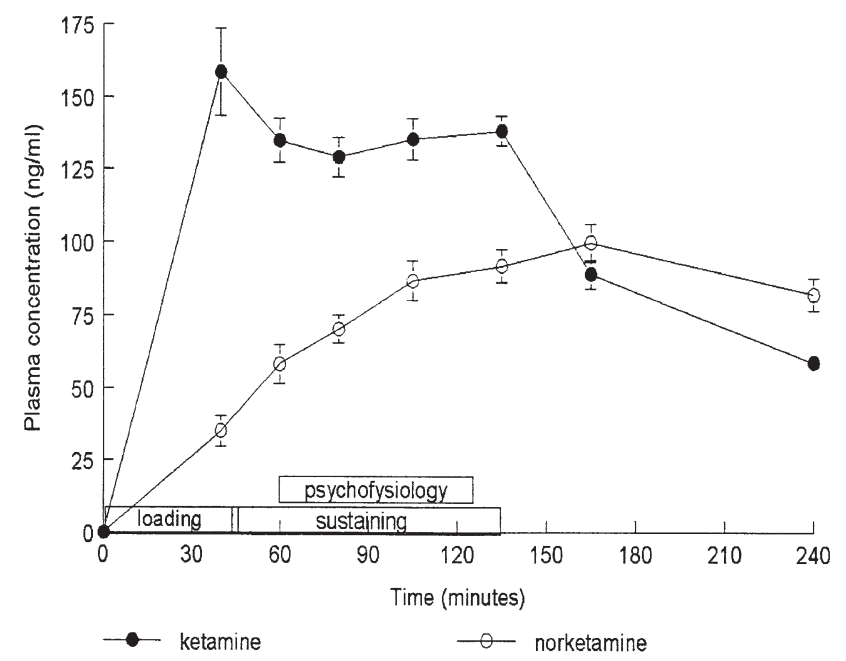

Figure 1. Plasma levels of ketamine and norketamine after i.v. administration of $0.3 \mathrm{mg} / \mathrm{kg}$ ketamine in a pseudo-steady state model in 18 healthy male subjects during the various stages in the study (see Methods: Biochemical Analysis). 
reaction time to hits. A response was considered a hit when it was given within a window of 200-1000 ms after stimulus presentation. Group means are presented in Table 1. No significant differences were found.

\section{ERP Data}

Grand average ERPs, PN, and MMN for both the control and ketamine condition are presented in Figures 2 and 3. Mean amplitudes of the auditory N1, and P3 are presented in Table 2. Mean amplitudes of the PN to standards and MMN to non-attended stimuli are presented in Table 3.

N100. A stimulus type main effect was found $[F(1,17)=$ $6.46 ; p<.05]$. In addition, a condition $\mathrm{x}$ stimulus type effect was found $[\mathrm{F}(1,17)=4.46 ; p<.05]$. When tested per stimulus type, a condition main effect was found in the case of the deviant stimuli $[\mathrm{F}(1,17)=4.37 ; p<.05]$ : the response of the subjects to the deviant stimuli (attended or non-attended) being larger in the ketamine condition than in the placebo condition.

P300. A condition main effect $[\mathrm{F}(1,17)=5.78 ; p<$ $.05]$, an attention main effect $[\mathrm{F}(1,17)=44.66 ; p<.001]$, a stimulus type main effect $[\mathrm{F}(1,17)=71.42 ; p<.001]$, and an attention $\mathrm{x}$ stimulus type interaction effect $[\mathrm{F}(1,17)=46.10 ; p<.001]$ were found. When tested per stimulus type (planned comparison), it was found that the response of the subjects to the deviant stimuli (attended or non-attended) was larger in the placebo condition than in the ketamine condition $[\mathrm{F}(1,17)=6.41 ; p<.05]$.

Difference Waves. Mismatch negativity (MMN) and processing negativity $(\mathrm{PN})$ were found in both the placebo and ketamine condition: $[\mathrm{F}(1,17)=223.03$; $p<$ $.001]$ and $[\mathrm{F}(1,17)=72.62 ; p<.001]$, respectively (expressed as a difference from zero). In the case of $\mathrm{PN} \mathrm{a}$ significant reduction in amplitude was found in the ketamine condition when compared to the placebo condition $(\mathrm{t}=2.52 ; p<.05)$. MMN showed no significant differences between the ketamine and placebo condition.

\section{DISCUSSION}

This study reports the effects of a sub-anaesthetic dose of the non-competitive NMDA antagonist, ketamine, on hu-

Table 1. Mean Performance Data of Placebo and Ketamine Condition

\begin{tabular}{lccc}
\hline Condition & $\begin{array}{c}\text { Hits } \\
\text { (SD) \% }\end{array}$ & $\begin{array}{c}\text { False alarms } \\
\text { (SD) \% }\end{array}$ & $\begin{array}{c}\text { Reaction time } \\
\text { (ms) }\end{array}$ \\
\hline Placebo & $96.9(2.07)$ & $0.44(1.53)$ & $597(108)$ \\
Ketamine & $97.9(1.60)$ & $0.34(1.07)$ & $566(86)$ \\
\hline
\end{tabular}

man selective attention. Our aim was to induce attentional anomalies in healthy control subjects by (non-competitively) antagonizing NMDA receptor transmission to mimic the attention abnormalities often observed in schizophrenic patients. Ketamine was, therefore, expected to lead to reduced performance, reduced mismatch and processing negativity, and reduced P300 to deviant stimuli (see Verbaten and van Engeland 1995, for a review).

In this study no significant difference could be detected on a behavioral level between the placebo and ketamine condition (i.e., reaction times for and percentages of hits and false alarms). Baribeau-Braun et al. (1983) found that schizophrenic patients performed a selective attention task more slowly and less accurately than control subjects. Thus, at the behavioral level, ketamine does not appear to affect human attention as observed to be present in schizophrenia. However, the initial dose of ketamine was relatively low $(0.3 \mathrm{mg} / \mathrm{kg})$ and the time period of infusion relatively long (40 minutes) in comparison to other studies, although the dose was sufficient to raise BPRS total score (reported in (van Berckel et al. 1998)).

Newcomer et al. (1999) used loading doses of 0.27, 0.081 , and $0.024 \mathrm{mg} / \mathrm{kg}$ administered over an infusion period of 10 minutes, followed by lower maintenance doses than in the present study. Similar to this study, they found increases in the BPRS scores in the ketamine condition. In addition, Krystal et al. (1998) found increases in BPRS after administration of a bolus of 0.26 $\mathrm{mg} / \mathrm{kg}$ ketamine followed by an infusion of $0.65 \mathrm{mg} / \mathrm{kg}$ per hour. Lahti et al. (1995) administered doses of 0.1, 0.3 , and $0.5 \mathrm{mg} / \mathrm{kg}$ of ketamine intravenously over 60 seconds to healthy volunteers after which they were challenged in a visual vigilance task. In this task, the subjects attended to numbers that were presented on a screen and had to push a button whenever a ' 9 ' was preceded by a ' 1 '. Only the highest dose of ketamine increased the number of errors made.

Mismatch negativity to the unattended stimuli was found in both the placebo and ketamine condition. Schizophrenic patients show reduced MMN (Javitt et al. 1993, 1995; Shelley et al. 1991), that cannot be accounted for by neuroleptic medication (Catts et al. 1995). Therefore, if ketamine was able to induce transient 'schizophrenic-like' effects in healthy controls, MMN would have been attenuated in the ketamine condition. However, this was not found. Moreover, the absence of attenuated MMN in the ketamine condition contrasts with findings from the study of Javitt et al. (1996) in monkeys, in which both competitive and noncompetitive NMDA antagonists blocked MMN. The failure to find this effect may be due to the dose of ketamine used in our study. For instance, one of the findings of Malhotra et al. (1996) was a significant decrement in attention after administration of a bolus of $0.12 \mathrm{mg} / \mathrm{kg}$ followed by infusion of $0.65 \mathrm{mg} / \mathrm{kg}$ to healthy volunteers. 
Placebo

FZ

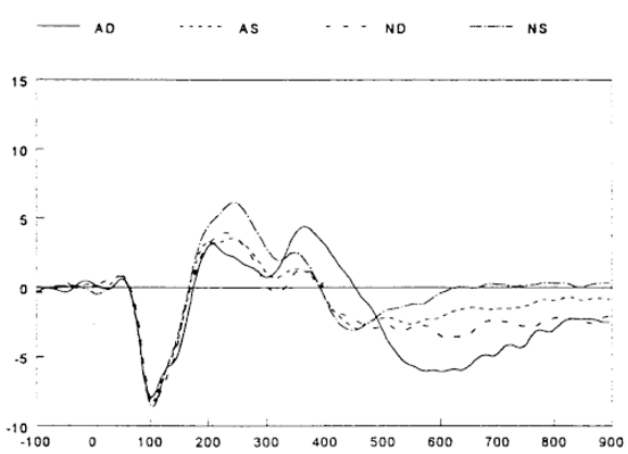

$\mathrm{CZ}$

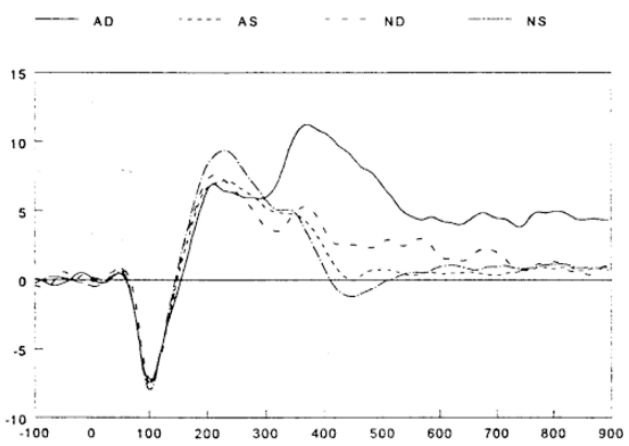

$\mathrm{PZ}$
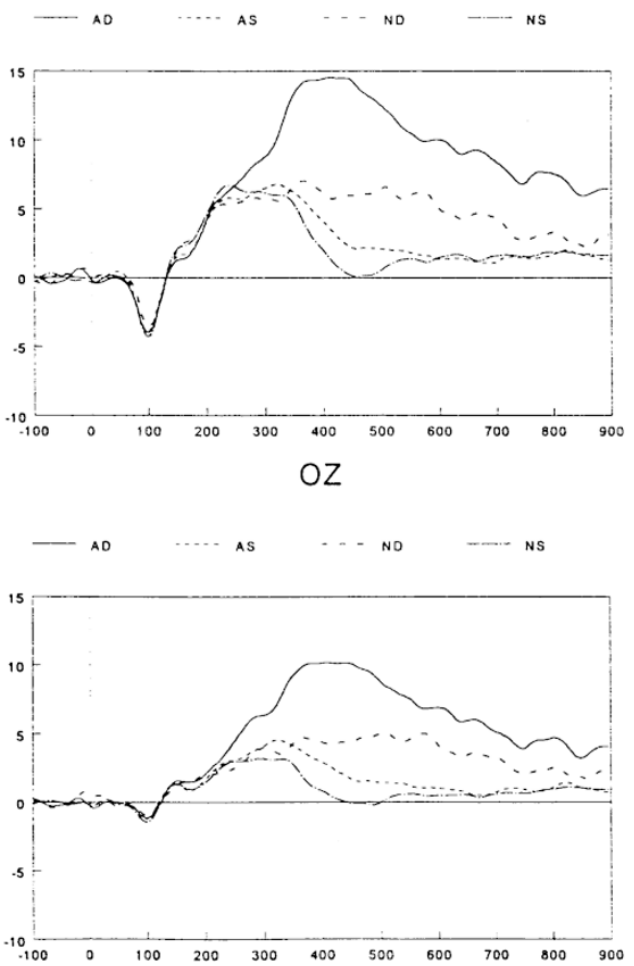

\section{Ketamine}

$\mathrm{FZ}$

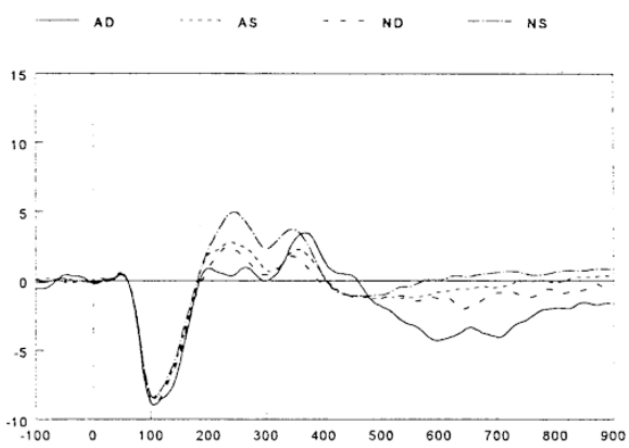

CZ

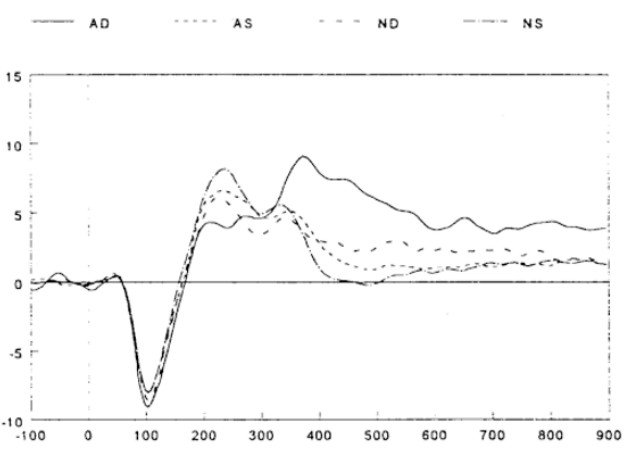

$\mathrm{PZ}$
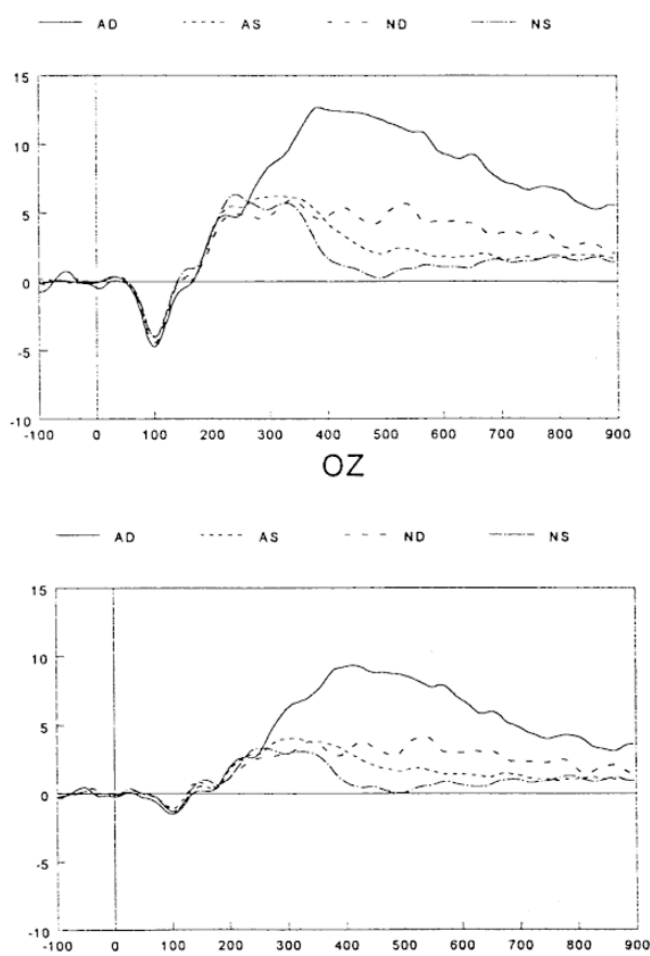

Figure 2. Grand average ERPs per lead for the placebo and ketamine condition. AD, attended deviant; AS, attended standard; ND, non-attended deviant; NS, non-attended standard. 

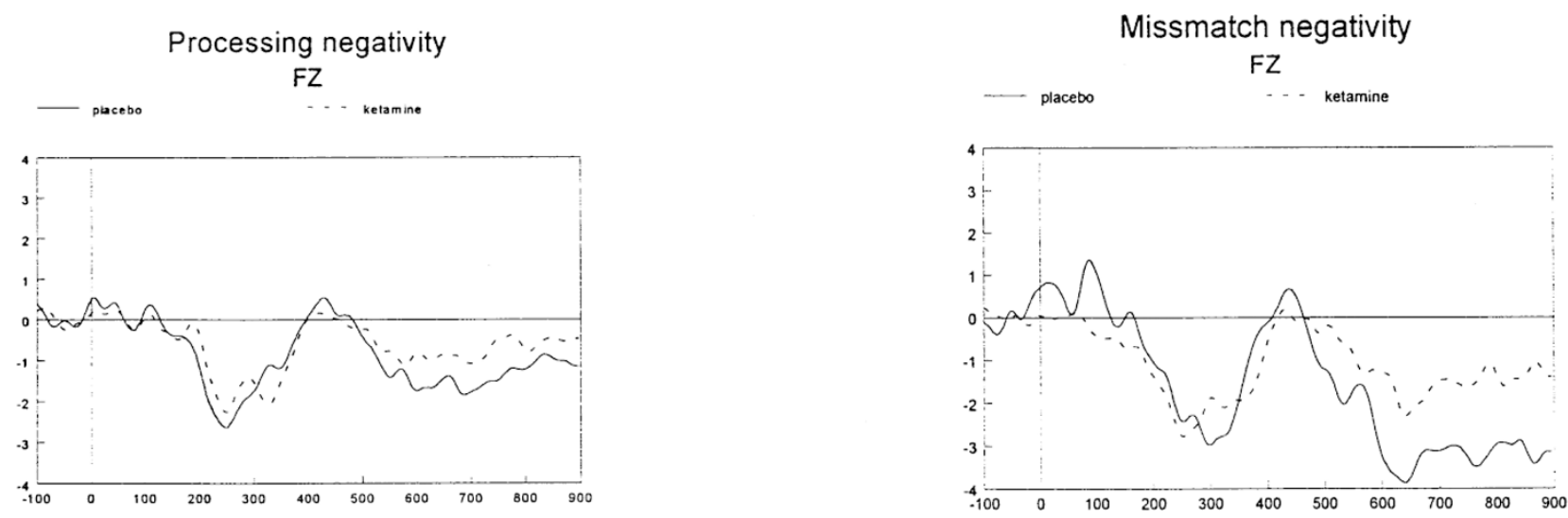

Figure 3. Grand average difference waves to standard stimuli (processing negativity) and non-attended standard/deviant stimuli (mismatch negativity).

Processing negativity to standard stimuli was found in both the placebo and ketamine condition. However, in the ketamine condition the PN was significantly reduced as compared to the placebo condition, suggesting that ketamine induces attentional abnormalities in healthy subjects at the ERP level. This result is consistent with the findings reported by Ward et al. (1991).

In the present study, ketamine induced a decrease of the P300 to all stimuli (condition main effect) and to deviant stimuli, in particular. Similarly, in the study of Baribeau-Braun et al. (1983), schizophrenic patients showed a reduced P300 to all stimulus types as compared to healthy controls. Ward et al. (1991) found a reduced P300 to target stimuli in schizophrenic patients when compared to healthy controls. However, the latter only considered target stimuli and ignored the unattended deviant stimuli, making a comparison with the present study difficult. Consequently, similar to the data of the PN, this result suggests that ketamine induces P300 abnormalities in healthy subjects that are commonly observed in schizophrenic patients.

A significant enhancement of the N100 was found in the ketamine condition, induced by deviant stimuli only (whether attended to or not). In an extensive review article, Näätänen and Picton (1987) describe six different components which might contribute to the
N100 wave form. Three of the components described in the review article are related to MMN or PN of which the onset latency was too late to influence the N100 in the present study (see Figure 3). Two other components are suggested to be related to stimulus intensity and the startle reflex respectively. However, all stimuli used in the present study were of equal intensity $(95 \mathrm{~dB})$ and not intense enough to elicit a startle response. This leads to the conclusion that component 2 (which is presumably generated in the superior temporal gyrus and activated by connections from the primary auditory cortex and possibly from the thalamus) might have been influenced by ketamine in the present study. However, it is unclear whether this enhanced N100 reflects symptoms of schizophrenia.

In summary, the results regarding the P300 and PN data support the notion that ketamine induces 'schizophrenia-like' symptoms in healthy volunteers. However, the results concerning the mismatch negativity and the performance data appear at odds with this concept, which, most likey, is the result of the low dose of ketamine used in the present study.

Since N100, P300 potential, mismatch negativity, and processing negativity, all represent basal mechanisms of attention and stimulus processing, anomalies in these measures may give rise to an altered perception

Table 2. Mean ERP Amplitudes (uV) per Channel, Stimulus Type, and Leads for Both Conditions

\begin{tabular}{|c|c|c|c|c|c|c|c|c|c|c|c|c|c|c|c|c|}
\hline \multirow{3}{*}{$\begin{array}{l}\text { ERP and } \\
\text { condition }\end{array}$} & \multicolumn{8}{|c|}{ Attended } & \multicolumn{8}{|c|}{ Non-attended } \\
\hline & \multicolumn{4}{|c|}{ Standards } & \multicolumn{4}{|c|}{ Deviants } & \multicolumn{4}{|c|}{ Standards } & \multicolumn{4}{|c|}{ Deviants } \\
\hline & $\mathrm{Fz}$ & $\mathrm{Cz}$ & $\mathrm{Pz}$ & $\mathrm{Oz}$ & $\mathrm{Fz}$ & $\mathrm{Cz}$ & $\mathbf{P z}$ & $\mathrm{Oz}$ & $\mathbf{F z}$ & $\mathrm{Cz}$ & $\mathrm{Pz}$ & $\mathrm{Oz}$ & $\mathbf{F z}$ & $\mathrm{Cz}$ & $\mathrm{Pz}$ & $\mathrm{Oz}$ \\
\hline \multicolumn{17}{|l|}{ N1 } \\
\hline Control & -8.6 & -7.9 & -4.2 & -1.6 & -8.5 & -7.9 & -4.8 & -2.3 & -9.0 & -8.2 & -4.5 & -1.7 & -9.1 & -8.1 & -4.3 & -1.7 \\
\hline Ketamine & -8.9 & -8.2 & -4.2 & -1.5 & -9.8 & -9.5 & -5.1 & -2.4 & -8.9 & -8.3 & -4.4 & -1.7 & -9.4 & -8.9 & -4.7 & -2.2 \\
\hline \multicolumn{17}{|l|}{ P300 } \\
\hline Control & 3.1 & 6.7 & 7.8 & 5.3 & 5.8 & 12.8 & 16.8 & 12.1 & 4.7 & 7.3 & 7.3 & 4.1 & 3.5 & 7.5 & 9.8 & 7.1 \\
\hline Ketamine & 3.1 & 6.1 & 7.3 & 4.9 & 4.4 & 11.0 & 15.4 & 10.9 & 4.7 & 6.5 & 6.4 & 3.8 & 3.0 & 6.4 & 8.0 & 5.7 \\
\hline
\end{tabular}


Table 3. Mean Amplitudes of Processing Negativity to Standard Stimuli and Mismatch Negativity to Non-Attended Stimuli

\begin{tabular}{|c|c|c|c|c|c|c|c|c|}
\hline \multirow[b]{2}{*}{ Condition } & \multicolumn{4}{|c|}{ Processing Negativity } & \multicolumn{4}{|c|}{ Miss-match Negativity } \\
\hline & $\mathrm{Fz}$ & $\mathrm{Cz}$ & $\mathbf{P z}$ & $\mathrm{Oz}$ & $\mathrm{Fz}$ & $\mathrm{Cz}$ & $\mathrm{Pz}$ & $\mathrm{Oz}$ \\
\hline Control & -3.5 & -3.2 & -2.2 & -1.1 & -5.2 & -5.0 & -3.8 & -2.4 \\
\hline Ketamine & -2.7 & -2.3 & -1.6 & -1.2 & -4.5 & -4.1 & -2.9 & -2.1 \\
\hline
\end{tabular}

(which, in turn, might ultimately lead to the development of psychotic symptoms) and/or cognitive deficits (i.e., impairments of memory and learning abilities), aspects that are core to schizophrenia. Indeed, several studies report ketamine-induced distortions of these processes in healthy volunteers (Krystal et al. 1998; Newcomer et al. 1999; Adler et al. 1998), and/or an acute (short lived) increase of psychotic symptoms in schizophrenic patients (Lahti et al. 1995; LaPorte et al. 1996; Malhotra et al. 1997). In the study of LaPorte et al. (1996), bolus injections of ketamine $(0.5 \mathrm{mg} / \mathrm{kg})$ did not alter memory recall of previously learned verbal or figural memory tasks in schizophrenic patients. The authors concluded that once material is learned, NMDA antagonists do not influence subsequent recall. In the study of Newcomer et al. (1999), a dose-dependent decrease in learning and memory performance on both a verbal and non-verbal declarative memory task was found. In addition, Adler et al. (1998) found ketamineinduced impairments in working and semantic memory in healthy volunteers.

The data of the present study support the results of the studies reviewed above: the processes at the basis of attention and memory (represented by a reduced P300, processing negativity and probably an enhanced N100) appear to be disrupted by ketamine, thus preventing material being learned properly, while not preventing recall of previously learned material. Additional evidence that reduced glutamatergic activity in the brain is involved in recall and memory difficulties in schizophrenia is presented in the study of Malhotra et al. (1997). They found further decrements in recall and recognition memory in schizophrenic patients and an exacerbation of positive and negative symptoms after administration of ketamine. In the present study, no evidence was found for an effect of ketamine on an even more basal mechanism of attention, the gating of sensory stimuli (measured by the prepulse inhibition of the startle reflex and the suppression of the P50 potential (Van Berckel et al. 1998).

In conclusion, ketamine induces some of the attention deficits in healthy controls which are usually found in schizophrenic patients. Consequently, reduced glutamatergic activity in the brain could be involved in, at least, some of the (cognitive) symptoms of schizophrenia.

\section{REFERENCES}

Adler CM, Goldberg TE, Malhotra AK, Pickar D, Breier A (1998): Effects of ketamine on thought disorder, working memory, and semantic memory in healthy volunteers. Biol Psychiatry 43:811-816

Andreasen NC, Flaum M, Arndt S (1992): The comprehensive assessment of symptoms and history (CASH): An instrument for assessing psychopathology and diagnosis. Arch Gen Psychiatry 49:615-623

Baribeau-Braun J, Picton TW, Gosselin JY (1983): Schizophrenia: A neurophysiological evaluation of abnormal information processing. Science 219:874-876

Boutros N, Nasrallah H, Leighty R, Torello M (1997): Auditory evoked potentials, clinical vs. research applications. Psychiatry Res 69:183-195

Catts SV, Shelley AM, Ward PB, Liebert B, Mcconaghy N, Andrews S, Michie PT (1995): Brain potential evidence for an auditory sensory memory deficit in schizophrenia. Am J Psychiatry 152:213-219

Domino EF, Chodoff P, Corrsen G (1965): Pharmacologic effects of CI-581, a new dissociative anesthetic, in man. Clin Pharmacol Therap 6:279-291

Ellison G (1995): The N-methyl-D-aspartate antagonists phencyclidine, ketamine and dizocilpine as both behavioral and anatomical models of the dementias. Brain Res Rev 20:250-267

Endicott J, Spitzer RL (1978): A diagnostic interview: The schedule for affective disorders and schizophrenia. Arch Gen Psychiatry 35:837-844

Friedman D (1991): Endogenous scalp-recorded brain potentials in schizophrenia: A methodological review. In Steinhauer SR, Gruzelier JH, Zubin J (eds), Neuropsychology, Psychophysiology, and Information Processing. Amsterdam, The Netherlands, Elsevier Science Publishing Co, pp 91-127

Grotta J, Clark W, Coull B, Pettigrew LC, Mackay B, Goldstein LB, Meissner I, Murphy D, LaRue L (1995): Safety and tolerability of the glutamate antagonist CGS 19755 (Selfotel) in patients with acute ischemic stroke. Results of a phase IIa randomized trial. Stroke 26:602-605

Javitt DC, Doneshka P, Zylberman I, Ritter W, Vaughan HG (1993): Impairment of early cortical processing in schizophrenia: An event-related potential confirmation study. Biol Psychiatry 33:513-519

Javitt DC, Doneshka P, Grochowski S, Ritter W (1995): Impaired mismatch negativity generation reflects widespread dysfunction of working memory in schizophrenia. Arch Gen Psychiatry 52:550-558 
Javitt DC, Steinschneider M, Schroeder CE, Arezzo JC (1996): Role of cortical N-methyl-D-aspartate receptors in auditory sensory memory and mismatch negativity generation: Implications for schizophrenia. Proc Natl Acad Sci USA 93:11962-11967

Jonkman LM, Kemner C, Verbaten MN, Koelega HS, Camfferman G, van der Gaag R, Buitelaar JK, van Engeland $H$ (1997): Event-related potentials and performance of Attention-Deficit Hyperactivity Disorder: Children and normal controls in auditory and visual selective attention tasks. Biol Psychiatry 41:595-611

Juckel G, Mullerschubert A, Gaebel W, Hegerl U (1996): Residual symptoms and P300 in schizophrenic outpatients. Psychiatry Res 65:23-32

Kenemans JL, Molenaar PC, Verbaten MN, Slangen JL (1991): Removal of the ocular artifact from the EEG: A comparison of time and frequency domain methods with simulated and real data. Psychophysiology 28:114-121

Krystal JH, Karper LP, Seibyl JP, Freeman GK, Delaney R, Bremner JD, Heninger GR, Bowers MB Jr, Charney DS (1994): Subanesthetic effects of the noncompetitive NMDA antagonist, ketamine, in humans. Psychotomimetic, perceptual, cognitive, and neuroendocrine responses. Arch Gen Psychiatry 51:199-214

Krystal JH, Karper LP, Bennett A, D'Souza DC, Abi Dargham A, Morrissey K, Abi Saab D, Bremner JD, Bowers MB Jr, Suckow RF, Stetson P, Heninger GR, Charney DS (1998): Interactive effects of subanesthetic ketamine and subhypnotic lorazepam in humans. Psychopharmacology 135:213-229

Lahti AC, Koffel B, LaPorte D, Tamminga CA (1995): Subanesthetic doses of ketamine stimulate psychosis in schizophrenia. Neuropsychopharmacology 13:9-19

LaPorte DJ, Lahti AC, Koffel B, Tamminga CA (1996): Absence of ketamine effects on memory and other cognitive functions in schizophrenia patients. J Psychiatric Res 30:321-330

Luby ED, Gottlieb JS, Cohen BD, Rosenbaum G, Domino EF (1962): Model psychoses and schizophrenia. Ame J Psychiatry 119:61-67

Malhotra AK, Pinals DA, Weingartner H, Sirocco K (1996): NMDA receptor function and human cognition: The effects of ketamine in healthy volunteers. Neuropsychopharmacology 14:301-307

Malhotra AK, Pinals DA, Adler CM, Elman I, Clifton A, Pickar D, Breier A (1997): Ketamine-induced exacerbation of psychotic symptoms and cognitive impairment in neuroleptic-free schizophrenics. Neuropsychopharmacology 17:141-150

McGhie A, Chapman J (1961): Disorders of attention and perception in early schizophrenia. Br J Med Psychol 34:103-116

Näätänen R (1979): Orienting and evoked potentials. In Kimmel HD, Olst EH, Orlebeke JF (eds), The Orienting Reflex in Humans. Erlbaum, Hillsdale, NJ, pp 61-75

Näätänen R (1990): The role of attention in auditory information processing as revealed by event-related potentials and other brain measures of cognitive function. Behav Brain Sci 13:201-288

Näätänen $R$, Paavilainen $\mathrm{P}$, Tiitinen $\mathrm{H}$, Jiang D, Alho K
(1993): Attention and mismatch negativity. Psychophysiology 30:436-450

Näätänen R, Picton TW (1987): The N1 wave of the human electric and magnetic response to sound: A review and an analysis of the component structure. Psychophysiology 24:375-425

Newcomer JW, Farber NB, Jevtovic Todorovic V, Selke G, Melson AK, Hershey T, Craft S, Olney JW (1999): Ketamine-induced NMDA receptor hypofunction as a model of memory impairment and psychosis. Neuropsychopharmacology 20:106-118

Oades RD, Dittmann Balcar A, Zerbin D, Grzella I (1997): Impaired attention-dependent augmentation of MMN in nonparanoid vs. paranoid schizophrenic patients: A comparison with obsessive-compulsive disorder and healthy subjects. Biol Psychiatry 41:1196-1210

Öhman A (1979): The orienting response, attention, and learning: An information-processing perspective. In Kimmel HD, Olst EH, Orlebeke JF (eds), The Orienting Reflex in Humans. Erlbaum, Hillsdale, NJ, pp 443-471

Pritchard WS (1986): Cognitive event-related potential correlates of schizophrenia. Psychol Bull 100:43-66

Sams M, Paavilainen P, Alho K, Näätänen R (1985): Auditory frequency discrimination and event-related potentials. Electroencephal Clin Neurophysiol Evoked Potentials 62:437-448

Shelley AM, Ward PB, Catts SV, Mitchie PT, Andrews S, Mcconaghy N (1991): Mismatch negativity: An index of a preattentive processing deficit in schizophrenia. Biol Psychiatry 30:1059-1062

Strik WK, Dierks T, Kulke H, Maurer K, Fallgatter A (1996): The predictive value of P300-amplitudes in the course of schizophrenic disorders. J Neural Transm 103:1351-1359

Toru M, Watanabe S, Shibuya H, Nishikawa T, Noda K, Mitsushio H, Ichikawa H, Kurumaji A, Takashima M, Mataga N, Ogawa A (1988): Neurotransmitters, receptors and neuropeptides in post-mortem brains of chronic schizophrenic patients. Acta Psychiatr Scand 78:121-137

Tsai G, Passani LA, Slusher BS, Carter R, Baer L, Kleinman JE, Coyle JT (1995): Abnormal excitatory neurotransmitter metabolism in schizophrenic brains. Arch Gen Psychiatry 52:829-836

van Berckel BNM, Hijman R, van der Linden JA, Westenberg HG, van Ree JM, Kahn RS (1996): Efficacy and tolerance of D-cycloserine in drug-free schizophrenic patients. Biol Psychiatry 40:1298-1300

van Berckel BNM, Oranje B, Ree JMv, Verbaten MN, Kahn RS (1998): The effects of low dose ketamine on sensory gating, neuroendocrine secretion and behavior in healthy human subjects. Psychopharmacology 137:271-281

Venables PH (1991): Overview of psychophysiology in relation to psychopathology with special reference to schizophrenia. In Steinhauer SR, Gruzelier JH, Zubin J (eds), Neuropsychology, Psychophysiology, and Information Processing. Amsterdam, The Netherlands, Elsevier Science Publishing Co, pp 3-37

Verbaten MN, van Engeland H (1995): (Neuro)physiologic similarities between childhood developmental disorders 
and schizophrenia. In Den Boer JA, Westenberg HGM, Van Praag HM (eds), Advances in the Neurobiology of Schizophrenia. Chichester, New York, Brisbane, Toronto, Singapore, Wiley \& Sons Ltd, pp 369-400

Ward PB, Catts SV, Fox AM, Michie PT, Mcconaghy N (1991): Auditory selective attention and eventrelated potentials in schizophrenia. Br J Psychiatry 158: 534-539
Woldorff MG, Hackley SA, Hillyard SA (1991): The effects of channel-selective attention on the mismatch negativity wave elicited by deviant tones. Psychophysiology 28:30-42

Woldorff MG, Hillyard SA (1991): Modulation of early auditory processing during selective listening to rapidly presented tones. Electroencephal Clin Neurophysiol 79:170-191 